\title{
Dramatising the Hidden Hurt: acting against covert bullying by adolescent girls
}

\author{
Bruce Burton* \\ bruce.burton@griffith.edu.au
}

School of Education and Professional Studies (B\&L), Faculty of Education, Mt.Gravatt Campus, Griffith University, Queensland Australia, 4122

This paper, delivered at the IDIERI Conference in Sydney in July 2009, explores the outcomes of a project designed to apply the applied theatre techniques developed for the Acting Against Bullying program to the specific problem of covert or hidden bullying by adolescent girls.

Conducted in a large all girls' school, the research reveals some significant new information about the nature of covert bullying. It also provides confirmatory evidence of the efficacy of Drama in enhancing identification, empathy and self-esteem in adolescent girls to enable them to deal more effectively with relational aggression. The project is on-going in 2010.

\section{The Project}

The Hilltop School in Brisbane, Australia is a large, private, all girls' school of over 1000 pupils with classes at all year levels from Year 1 to Year 12. The students are not all from privileged or stable families, and a significant number of them are international students, mainly from Asia, with a range of ethnic, cultural and religious backgrounds. The Principal and the Dean of Students at the school were aware of recent research that indicates bullying in schools world-wide is escalating rapidly, and some cases of serious bullying had come to light over a period of time within the school. However, there was no clear indication of the full nature or extent of the problem, and like the majority of schools in Australia, Hilltop School had a written policy for dealing with bullying, but no whole - school, proactive, anti-bullying program in place. Because the Acting against Bullying program developed at Griffith University had received extensive exposure in the media and at conferences on bullying and child safety, I was approached to implement the program throughout the school over a two year period.

The challenge was an interesting one. The most recent research in Australia suggests that social bullying by girls in single sex private schools, particularly covert bullying and cyber bullying, is more widespread and more intense than amongst girls at co-educational, state schools (McDougall, B. and Chilcott, T. 2009). Furthermore, the Acting Against Bullying program had been conducted entirely in state government schools and had not specifically focused on gender-based or particular forms of bullying. The Hilltop project therefore provided an opportunity to research both specific bullying amongst girls and the incidence of covert and cyber bullying in the private school environment as part of identifying and attempting to address the bullying occurring in the school.

The name of the school and of all students mentioned in this article have been changed to maintain anonymity. 


\section{Background}

The Acting Against Bullying Applied Theatre program was the result of ten years of action research into conflict and bullying in schools. It began in collaboration with the international DRACON research program into conflict within schools, with partners in Sweden, Malaysia and Australia. The program, using a combination of improvisation, process drama, forum theatre and peer teaching, evolved into an effective whole school program that impacted positively on bullying in both secondary and primary schools (O'Toole, J. Burton, B. \& Plunkett, A. 2005). In the final phase of the research in Australia, extensive data was collected by the researchers from Griffith University in Brisbane across a range of high schools and primary schools. The data clearly and consistently indicated that the combination of forum theatre and peer teaching enabled students of all ages to deal more effectively with bullying (Burton, B. 2008).

The key drama strategy bused in the Acting Against Bullying program is Enhanced Forum Theatre, which developed and refined Boal's (1979) original participatory form of theatre of the oppressed. Enhanced Forum Theatre involves the creation of a realistic play in three scenes, rather than the single scene structure of Boal's version.

The three parties to bullying, - the bully, the bullied and the bystander, and the three identifiable stages of escalation in bullying, are taught to the students both conceptually and through the drama work. These stages are defined as latent, emerging and manifest, the students are encouraged to improvise each of the three scenes of their Enhanced Forum Theatre plays to represent a specific stage in the escalation of the bullying they are exploring, and to incorporate the three parties involved in bullying. They are also encouraged to make sure there is a time lapse of that days or weeks between each scene, so there is a genuine development of the plot, the characters and the issue being explored, and a genuine understanding of how bullying develops. Having three scenes means that the audience can intervene early in scene one or scene two in a bullying situation, before it becomes critical.

As well as these alterations to the structure of Forum Theatre, the final enhancement involved the insertion of a number of participatory techniques, from process drama into theatrical performance - permitting the audience to stop the action and find out what the character was actually thinking at any point - and even inviting the audience to interview characters placed in a "hot seat" (O'Neill 1995). This fleshes out for the audience their contextual understanding, so that their interventions can be better informed and more aware of pitfalls. Boal too has moved to this kind of added improvisation, in some of his allied therapeutic theatre work, including the idea of putting the protagonist and the antagonist in the hot seat (1995: 123).

However, despite the success of Acting Against Bullying and many other evidence-based programs, there is extensive research to suggest that bullying has increased in intensity, or at least that school students have become increasingly concerned about bullying. Research and survey evidence indicating this is widely reported by the media. The Guardian of February 292008 proclaimed that UK schools were the worst in Europe for bullying, citing the 2008 British Council survey 
of bullying across Europe that found bullying in secondary schools was more prevalent in the UK than in the rest of Europe, and that $46 \%$ of UK secondary school pupils think that bullying is a problem in their schools. In Australia, the latest national survey of bullying conducted for the Federal Government indicated that $50 \%$ of all children are bullied at some stage in their schooling. Despite being completed in February 2009, the report has still not6 been officially released, but the key findings from the report were published in the Courier Mail newspaper on June 1, 2009 (McDougall and Chilcott 2009, 1-2).

The causes of this apparent increase are not clear. There is no doubt that the media, parents, teachers and students are more aware of bullying than in the past. The significant increase in student concern about bullying internationally may reflect this awareness rather than an actual increase. Furthermore, a review of the literature in 2005 revealed that: "... the incidence of serious bullying reported by students in schools throughout the developed world over the past decade has remained remarkably constant at 10\%( O'Toole et al $2005: 16$ ).

\section{Covert Bullying by Adolescent Girls}

The increasing awareness of bullying is particularly apparent in the area of covert or hidden bullying, especially amongst girls. There is an increasing body of literature on the subject of how girls bully, and the nature of relational aggression between girls (Crothers, L. M., Field, J. E., \& Kolbert, J. B. 2005, Besag, V. E. 2006, Leenaars, L.S., Dane, A.V., \& Marini, Z. (2008). It has traditionally been assumed that boys are the primary perpetrators of bullying and violence. However, recent studies on girls' aggressive behaviour in a number of countries have produced consistent findings that girls are aggressive toward each other but usually in more covert, indirect ways which are motivated by the relational goals concerned with the making and breaking of friendships. (Archer, J. \& Coyne, S. 2005; James, V.H. \& Owen, L.D. 2005).

In particular, girls demonstrate covert and indirect bullying in the form of rumour spreading and/or social exclusion, and they are increasingly using forms of verbal violence through electronic media such as the Internet, email and mobile phones (Kowalski, R., Limber, S. \& Agatston, P. 2007). Cyber bullying is rooted in relational aggression and is a growing issue, especially amongst adolescent girls, because of their extensive access to a range of ways to communicate and broadcast information among their peers. Ponsford (2007) found that teenage girls use electronic media to engage in social exclusion or the demotion of other girls from the social hierarchy. and their on-line communications are more extreme and direct than in the real world, focusing on gossip, criticisms of appearance, attacks on sexuality, declarations of disloyalty, and statements about desiring physical violence.

Within the school context, acts of relational aggression include gossiping, spreading rumours, ignoring, exclusion from friendship groups, isolation, alienation, writing hurtful letters and text messages, and stealing friends or boyfriends (Crothers et al., 2005). These are subtle form of attack, difficult for teachers and other adults to recognise and manage (Bauman, S. \& Del Rio, A. 2006). In school contexts, relational aggression is associated with the formation of social cliques and subtle verbal and psychological tactics used to injure other girls' feelings of social acceptance. 
Extensive studies have shown that frequent acts of aggression toward victims are related to increased loneliness for the victim, peer rejection, anxiety and depression and low self-esteem (Björkqvist et al., 2001; La Greca \& Harrison, 2005; Storch \& Masia-Warner, 2004; Underwood,2003). Approximately $15 \%$ of victims are distressed or even traumatised as a result of encounters with bullies. In some rare but highly publicized cases, relentless bullying can result in a victim committing suicide

There is also evidence that the long-term consequences are just as serous for the bullies. During their schooling bullies are more likely to be disengaged and exhibit problem behaviour, have juvenile records and achieve poorly in their studies, and these behaviours remain remarkably constant. As adults, school bullies are more likely to have been convicted of a serious crime and of drug taking. They are less likely than their peers to have achieved success academically, professionally or socially and are more likely to have children who are bullies (Roberts Jr. W.B. 2006 p. 59 - 60). Girls who bully are also specifically linked with adult depression and a prediction of early pregnancy (Besag, 2006; Miller-Johnson et al., 2005).

\section{Drama, Peer Teaching and Behavioural Change}

A major claim for the power of drama to effect behavioural change, especially in adolescents in schools, is the contention that it provides learners with opportunities to experience "reality" from different perspectives - creating the "distance" that is needed for young people to see themselves as "others" and as such appreciate different points of view (Fleming, 1998). Through role, emotional distance may be increased, so that the student learners can de-centre themselves from their own point of view (Byram, 1997). Bolton and Heathcote (1998) believe that individuals behave in certain ways based on their personal belief systems and their cultural belief systems.

The Hilltop project therefore investigated the impact on individual girls and groups of students when opportunities were provided for them to de-centre from their own personal and cultural codes by using role to explore personal and cultural positions related to covert bullying. By later reflecting on these positions and critically analysing personal responses to them, the students appeared to achieve a deeper understanding and appreciation of both self and other. Indeed, Neelands (2009) argues that through drama young people can be led to imagine and look for new ways of living together rather than against each other; to find a shared understanding and to create new models of pluralist community.

These possibilities are made available because, while most subjects in the school curriculum deal in knowledge outside the personal and subjective domains. The content of drama is human relationships, conflict and power. It operates through invoking both cognitive understanding and empathy, where drama students imitate and refract life through constructed, hypothetical (i.e. fictional) contexts and situations (Burton 1991, O'Toole, 1992, Young 2000). In drama, students enact realistic events and characters that can be manipulated and reflected upon, and issues of 
relationships are dealt with in a safe, fictional context. In this way, the participants are both actors and audience, able to experience fictional roles and situations, whilst perceiving and reflecting on the meaning of these experiences at the same time ( Boal 1996, O'Neill 1995, Bolton 1998). Recent research has indicated that secondary school students themselves prefer the use of drama strategies when learning about real world problems such as bullying in comparison with other forms of instruction (Crothers, Kolbert and Barker 2006).

In relation to peer teaching, extensive research over two decades has identified this approach as a particularly potent approach to stimulating learning in schools (Rubin and Herbert1988, Falchikov 2001, Gordon 2005, Belliveau 2007). These studies have found clear, convincing proof that peer teaching can be an extremely effective tool for improving learning in the classroom. Goodlad and Hirst

(1989) identify the positive impact that peer tutoring has on student self-esteem. The specific benefits of peer teaching for those doing the teaching are described by Rubin and Herbert (1998) as an increase in social and intellectual awareness; significant gains in empathy; the clear recognition that they could change habitual patterns of behaviour; and finally, that peer teaching empowered the students, increasing their sense of mastery and self-esteem.

Other research has focused on the effects of peer teaching on the students being taught. Rubin and Herbert (1998) claim that this form of learning is superior in the application of concepts, problem solving, attitude, motivation, group membership and leadership skills. Overall, the research has produced clear evidence that teenagers often learn more effectively from their peers than from traditional, teacher-centred instruction (Gordon 2005)

Furthermore, recent research on the use of peer teaching to re-engage negative leaders in secondary schools through peer teaching drama has clearly demonstrated that it has the power to transform the behaviours and attitudes of alienated students with serious problems who have a high status amongst their peers. Not only do these students re-engage in the schooling process, but their peer teaching experiences appear to reorient them towards positive leadership roles. (Morrison et al. 2006)

\section{Uncovering the Covert Bullying}

The implementation of the Hilltop project was conducted by a team of 8 graduates and final year students from the Applied Theatre degree at Griffith University who were particularly interested in the field, plus two experienced Drama teachers. The team were paid as professional applied theatre workers by the school, and began by implementing the Acting Against Bullying program in two Year 11 classes within the Drama curriculum, using the combination of learning about bullying, improvisation and enhanced forum theatre that had proved successful in earlier implementations. These Year 11 students then taught all the Year 9 classes in the school about bullying, using drama and peer teaching, and these classes in turn implemented the project in Years 7 and 5, who did the same in Years 4 and 3. In the 
second year of implementation, the year levels that had not experienced the program previously will be involved in both learning and teaching about bullying.

The first indications that covert bullying was a real issue in the school emerged from the very first reactions of the girls in the Year 11 Drama classes to the initial teaching about bullying, Their responses to the use of freeze frames and improvisations to explore bullying were extraordinary. The students were reluctant to discuss or enact any bullying scenarios, no matter how fictitious, and their body language during the early sessions was strikingly negative and defensive. This refusal to actively engage through drama in the program had not occurred at any other school where Acting Against Bullying had been implemented.

When asked to work in groups to devise fictional improvisations that generically illustrated the three parties to bullying (bully, buli8ed and bystander), and the stages bullying escalates through (latent, emerging and manifest), the majority of the students constantly watched the reactions of three giros in the class to the discussions and improvisational activities, even when these girls were not in their groups. Some of the students chose not to participate in the drama activities but were active in the discussions about bullying. Although the facilitators had indicated that the bullying scenarios being constructed should be fictional and used as illustrations of the explicit teaching about bullying that ahs taken place, some of the participants chose to improvise situations they insisted were real.

Discussions were held with the Dean of Students and the Drama teachers after the session to determine what issues needed to be addressed and what changes to the program might need to be made in the light of the extraordinary response of the students to the workshop. The discussion revealed that there was in fact evidence of systematic long-term bullying occurring in Year 11, and some the girls suspected of being the ring leaders were in the Drama class. However, the teachers had no clear evidence that these girls were guilty of organising the bullying, nor of its extent.

Furthermore, the classroom teachers did not feel they were competent to recognise or manage covert bullying. Besag (2006) notes that it can be extremely difficult to identify the instigator of gossip or to challenge a group who have deliberately excluded a girl from their friendship circle. The literature indicates that adolescent girls often attack their target using an intangible, subjective focus based on personal opinion such as criticism of physical attributes and personal characteristics, which makes it difficult for the victim to challenge or for adults to intervene (.Bauman \& Del Rio 2006).

An analysis of the questionnaire that was administered in the preliminary sessions with the Year 11 classes confirmed these initial observations and the information from the teachers. More than $60 \%$ of the respondents indicated that they had been involved in on-going, regular, relational bullying during the past year. The behaviors the students identified included exclusion, isolation, rumor - spreading, and texting and placing text photos and video on My Space and Face Book to insult, harass and intimidate. This figure of $60 \%$ is extraordinarily high for reported bullying by older students, even in the light of the most recent research, which indicates that bullying is most common between the ages of 9 and 15, and reduces significantly in Year 11. (McDougall and Chilcott 2009, 2). 
It appeared to be significant that these older students, who had been so reluctant to discuss or enact any bullying situations in the classroom, were willing to identity and quantify the extent and seriousness of the bullying occurring in their classes on the anonymous questionnaire, which was confidential and administered by the applied theatre team in the absence of the teachers. This suggested that the students were genuinely concerned about bullying but reluctant to expose themselves further covert bullying by revealing their experiences publicly in the classroom. It alos seemed especially signiifcnat that a number were preaperd tov to identify themselves as bullies on the questionnaire, or at least toi admnit to covert bullying behaviour.

In the light of the initial observations and particuallry the data from the questionnaire, it was decided to make more extensive use of classroom drama techniques in the project, before interiducing enhganced forum theatre. The stategies utilised included the construction of dramatic narratives about bullying, and the use of process dramas beginning with a bullying pretext (O'Neill 1995). The students were asked to dramatise a range of bullying scenarios, both spontaneous and prepared, that explored the nature of the bullying they believed was occurring at their school.

The intention was to offer the students the opportunity to investigate the causes and consequences of the covert bullying they had identified in the questionnaire by creating narratives based on personal experiences, but performed in the safe, fictional environment of drama. The initial workshop and the questionnaire had both offered evidence that the students were deeply concerned about bullying, but were also unwilling to publically identify their involvement in it or their experience of it. The fictionalisation and dramatisation of personal narratives offered the students a genuine choice about their level of involvement in the construction and performance of the narratives, and the extent to which these narratives were fiction. This appeared to be the best way to create the conditions for the students to explore and reflect on the covert bullying that was occurring, whilst providing them with protection any negative consequences.

\section{Identification Through Drama}

The third one hour session with the Year 11 classes witnessed a breakthrough in commitment to the project by the students during the discussion around the creation of a dramatic narrative involving a fictional bully, a person being bullied, and a bystander. The students were asked to decide what these three characters might be thinking, feeling and doing. The girls as a group identified very similar thoughts and feelings for the three characters, with only the actions being different. The students themselves were fascinated by this outcome, and in the construction of the dramatic narratives that followed, there was an intense concentration on the motives and emotions of the three parties to the bullying. The intensity, involvement and energy observed in the creation of these narratives were of a qualitatively higher order than any previous drama work by the group. Increasing empathy was evidenced, and overtly stated, for students being bullied, but there was also dramatic and reflective understanding expressed about the motives of the bullies, and their need for positive support to change their behaviour, as well as sanctions. 
This intense and thoughtful commitment to the process of exploring bullying continued throughout the four one hour sessions that were conducted in the following weeks, and a series of spontaneous dramas were created dealing with a range of covert bullying behaviours that the girls identified as of concern to them. During these sessions the Applied Theatre team increasingly became actively involved as participants in the improvisations and process dramas at the invitation of the girls. In an interesting modification of standard teacher - in role, the young, female applied theatre workers used questioning and modelling both within and outside their fictional roles to enhance the structure, performance and meaning of the dramas.

O'Neill notes the potential of spontaneous drama to generate new understanding in the participants:

For Dorothy Heathcote, taking on a role means that there is a need to "read" the situation, to harness relevant information from previous experience, and to realign this information so that new understanding becomes possible. Like Moreno, she believes that the most important aspect of taking on a role is its spontaneity. It is unplanned, unpremeditated, and as a result can constantly surprise the individual into new awareness. $(1995,80)$

There were increasing indications of the students being surprised into new awareness about bullying in the improvised dramas. Many of the spontaneous bullying improvisations that the students created were related to intense relationships between girls and friendships with boys, often with a strong sexual element involved. The research suggests there is often a sexualised dimension to bullying amongst older adolescent girls, including accusations of being a lesbian or of heterosexual promiscuity (Duncan (2004). The Hilltop girls themselves were surprised and even confronted at times when these themes emerged from their own spontaneous improvisations, but were able to acknowledge that much of the relational aggression occurring amongst their peers did arise from intense relationships with boys and other girls. Increasingly, their dramas explored ways of acknowledging and dealing with jealousy, sexuality and competition in relationships, and some of the spontaneous solutions that emerged were both creative and effective.

Another significant aspect of the engagement of the students in the dramatisation of bullying narratives was the desire to explore the full range of roles implicit in bullying situations - the bully, the victim and the bystander. Individual girls chose to experiment with role reversal, choosing to portray bullies carrying out the kind of bullying they had actually experienced. Warner $(1997,41)$ notes that "..participants in drama are very aware of their own elaborate engagement patterns. They are also very conscious of how they personally learn best and what kind of methods work to enhance their learning."

One student identified this learning clearly and concisely: 
Because I have been able to play the three roles: bully, bullied and bystander, I've been able to get into their heads to understand what they are really thinking. (Sarah 16)

The students in the Year 11 Drama classes were experienced in educational drama practices and able to exploit the possibilities for personal learning - and for encouraging effective learning engagement in others. In the later stages of the group work, particular students were nominated by the group to take on the roles of girls being bullied, often with the clear indication that they were bullies in reality. Sometimes reluctantly, but increasingly willingly, these girls accepted the roles and functioned in them with both conviction and commitment. There was also increasing observational evidence that all the students were manipulating the context of the drama to developing a more sophisticated understanding of the nature of covert bullying itself.

"Acting behaviour is an act of fiction-making involving Identification through action, the conscious manipulation of time and space and capacity for generalisation" (Bolton, Gavin 1998 , 258)

In their summative responses to the project, a number of the students indicated that they had come to understand the behaviour of bullies, and to identify more clearly the reasons for their actions.

Although they do hurt people, I believe some bullies are just misunderstood and are acting out because of family/personal problems. (Trish 16)

Yes, because I now understand that they could be bullying because of family troubles and they need help. (Amelia 15)

The students were also able to identify and generalise about the nature and consequences of covert bullying for those being bullied, and to offer strategies for dealing with it, both within the dramas and on the summative questionnaire when asked their attitude to girls being bullied after the project:

That they feel really low and embarrassed and rejected, because they are pretty much powerless to the bully. (Amy 16)

Sympathetic that they often can't stand up for themselves (Jodie 15)

More sympathetic, but at the same time they do have the ability to change things. (Annie 16)

\section{Understanding and Competency}

The increasing commitment of the Year 11 students, and their demonstration of effective learning about bullying through the drama, allowed us to implement the next phase of the project, which involved the girls in preparing to teach the Year 9 classes in the school utilising a prepared piece of enhanced form that performance about bullying (Burton 2008). As they prepared their peer teaching and their forum performance, all the students demonstrated to some degree that they had learned not 
only understanding of covert bullying form the drama work, but a sense of competence in dealing with their own experiences of bullying. As Bundy observes:

I conclude that the idea is not contained in the drama but in the response of percipients as (or after) they experience it. It requires them to make some association between the drama and previous personal experience or understanding. The idea emerges in the association. $(2003,177)$

As they planned the peer teaching and the creation of the forum theatre performances, the Year 11 students revealed that they had been able grasp the idea of covert bullying and to make sophisticated judgements about its nature and consequences. In particular, the level of identification generated by the drama allowed them to empathise with and understand the behaviour of bullies, the bullied and bystanders.

The bully won't be able to stop without intervention from another

- the bystander needs to make them realise the severity of the situation and the consequences, and offer help. (Sarah 16)

There are various ways, but the bystander can usually talk to the bully or the other bystanders. However, they can also inform someone out of the situation such as a parent, teacher or counsellor. (Danni 16)

Perhaps most significantly of all, more than $50 \%$ of the students answered positively the question on the summative questionnaire about what they would do in future if they encountered bullying. These answers indicated both an increased sense of informed competence in dealing with relational aggression:

I am often a bystander so I now am informed if various ways in which I can stop bullying or support the bullied. (Amelia 16)

I am more likely to inform someone (teacher or counsellor) or butt in to change the situation (Rachelle 15)

I would report to an adult or get directly involved by trying to reason with the bully and bullied and sort out the problem (Isabelle 16)

\section{Conclusion}

The peer teaching of the Year 9 students offered the strongest confirmatory evidence that their exploration of covert bullying through drama had transformed the behaviour and attitudes of the Year 11 students. Without exception, they were able to explain and demonstrate to the younger students the nature of covert bullying and the behaviour and feelings of the 
participants. The Year 11 peer teachers also offered the younger girls a number of valuable strategies for dealing with relational aggression. Some of the most effective and enthusiastic peer teachers were girls who had been identified, or who had self identified, as bullies.

Since their involvement in the project, there has been no incidents, or indications, of relational aggression amongst the Year 11 drama students, which is a significant change to the situation before the project. Their classroom teachers have also reported an improvement in attendance and in commitment to their studies by the students.

The Year 11 peer teachers also demonstrated real concern for the Year 9 girls when the drama revealed some of the covert bullying that was occurring at this level. Interestingly, the drama activities and the questionnaire applied to the Year 9 students revealed a much lower level of relational aggression amongst the younger girls than had been occurring in Year 11. Strong mentoring relationships developed, and have continued, between the Year 11 and Year 9 students, especially in regard to bullying, and again, some of the year 11 girls identified as bullies have been proactive in the development of these mentoring relationships.

As the project continues in 2010 , further evidence will emerge about the nature of covert bullying in the school, The research so far has clearly indicated that relational aggression amongst older adolescent girls may well be much more widespread and intense than the general data for bullying in schools is revealing. It is also evident that the use of applied theatre strategies to address covert bullying in schools can enable female students to develop both understanding and competence in dealing with the problem. 
Keywords: covert bullying; drama and forum theatre; bullying management in schools

\section{Notes on Contributor}

Professor Bruce Burton was appointed to the first Chair of Applied Theatre in be established in Australia. $\mathrm{Hi}$ is the author of eight books in the fields of applied theatre and drama education, and ahs researched widely on both fields, receiving five Australian Research Council Grants. His research with john O'Toole on the Acting Against Bullying project is widely recognised internationally, and eh ahs been a visiting scholar at Cambridge University, UK, and visiting professor at Boras University, Sweden.

\section{References}

Archer, J., \& Coyne, S. M. (2005). An integrated review of indirect, relational \& social aggression. Personality and Social Psychology Review, 9, 212-230

.Bauman, S. \& Del Rio, A. (2006). 'Preservice Teachers' Responses to Bullying Scenarios: Comparing Physical, Verbal and Relational Bullying', Journal of Educational Pyschology, Vol 98(1) 219-231.

Besag, V. E. (2006). Bullying among girls friends or foes? School Psychology International, 27: 535-551.

Björkqvist, K., Oesterman, K., Lagerspetz, K. M. J., Landau, S. F., Caprara, G. V., \& Fraczek, A. (2001). Aggression, victimization, and sociometric status:

Findings from Finland, Israel, Italy, and Poland. In J. M. Ramirez \& D. S.

Richardson (Eds.), Cross-Cultural Approaches to Research on Aggression and

Reconciliation New York: Nova Science Publishers

Boal, A. (1979) The Theatre of the Oppressed. London: Pluto.

.Boal, A. (1995) nThe Rainbow of Desire. London: Routledge.

Boal, A . (1996) "Politics, Education and Change". In Drama Culture and Empowerment: The IDEA Dialogues, edited by John O'Toole \& Kate Donelan. Brisbane: IDEA Publications.

Bolton, Gavin (1998). Acting in Classroom Drama: A Critical Analysis. Stoke-on-

Trent: Trentham.

Bolton, G. and Heathcote, D. 1998. Teaching culture through drama. In Language learning in intercultural perspective, ed. Michael Byram and Michael Fleming. Cambridge: Cambridge University Press.

Bundy, Penny (2003). Aesthetic Engagement in the Drama Process. Research in Drama Education, 8 (2), p. 171-181.

Burton, Bruce. 2008 Acting Against Bullying in Schools O'Brien, Angela \& Donelan, Kate (2008) (Eds) The Arts and Youth at Risk: Global and Local Challenges. Cambridge Scholars Publishing, Newcastle upon Tyne, UK 139-155

Burton, Bruce. 1991. The Act of Learning: The Drama-Theatre Continuum in the Classroom. Melbourne: Longman Cheshire.

Byram, M. 1997. Teaching and assessing intercultural communicative competence. Clevedon: Multilingual Matters

Crick, N. R. and Grotpeter, J. K. (1995) Relational aggression, gender and social psychological adjustment. Child Development 66: 710-22. 
Crothers, L. M., Field, J. E., \& Kolbert, J. B. (2005). Navigating power, control and being nice: Aggression in adolescent girls' friendships. Journal of Counselling and Development, 83: 349354.

Fleming, M. 1998. Cultural awareness and dramatic art forms. In Language learning in intercultural perspective, ed. Michael Byram and Michael Fleming. Cambridge: Cambridge University Press.

James, V. H., \& Owens, L. D. (2005). They turned around like I just wasn't there:

An analysis of teenage girls' letters about their peer conflicts. School Psychology International, 26: 71-88.

Kowalski, R., Limber, S. \& Agatston, P (2007). Cyber Bullying: Bullying in the Digital Age. Malden,MA: Blackwell Publishers.

Leenaars, L.S., Dane, A.V., \& Marini, Z. (2008) Evolutionary perspective on indirect victimization in adolescence: the role of attractiveness, dating and sexual behavior. Aggressive Behavior, 34 (4): 404-415.

McDougall, Bryan and Chilcott, Tanya.(2009) Bullying is Out of Control in Schools The Courier Mail June 12009 Brisbane : Associated Newspapers

Morrison, Morag, B. Burton, and J. O'Toole. 2006. "Re-engagement through Peer Teaching Drama - Insights into Reflective Practice." In Burnard, P. and Hennessy, S. Reflective Practices in Arts Education. Netherlands: Springer

Neelands, J. 2009. Acting together: ensemble as a democratic process in art and life.

Research in Drama Education: The Journal of Applied Theatre and Performance 14, no.2: 173-189.

Nicholson, Helen. 2005. Applied Drama: The Gift of Theatre. UK: Palgrave Macmillan. O'Neill, Cecily. 1995. Drama World: A Framework for Process Drama. Portsmouth NH: Heinemann.

O'Toole, John, B. Burton and A. Plunkett. 2005. Cooling Conflicts: A New Approach to Conflict and Bullying in Schools. Sydney: Pearson Education.

Owens, L., Shute, R., \& Slee, P. (2000). "Guess what I just heard!": Indirect aggression among teenage girls in Australia. Aggressive Behaviour, 26: 67-83.

Ponsford, J. (2007) The Future of Adolescent Female Cyber-bullying: Electronic

Media's Effect on Aggressive Communication. Honors Thesis, Texas State University.

Powell, Kenneth E., et al. 1994. "A Review of Selected School-based Conflict Resolution and Peer Mediation Projects." Journal of Social Health, vol. 65, no. 10 (1995) 427 - 431

Remillard, A. M., \& Lamb, S. (2005). Adolescent girls coping with relational aggression. Sex Roles, 53, 221-231

Rigby, Ken. 2002. New Perspectives on Bullying. London: Jessica Kingsley. Underwood, M. K. (2003). Social Aggression Among Girls. New York: The Guilford Press. Roberts Jr., W.B. (2006) Bullying From Both sides :" Strategic interventions for working with bullies and victims California Corwin Press

Shakeshaft,. C., Baeber, E., Hergenrother, M., Jihnson,Y., Mandall, L. and Sawyer,J. (1995)

Peer harassment in schools Journal for a Just and Caring Education Vol. 130 - 44

Storch, E. A., \& Masia-Warner, C. (2004). The relationship of peer victimization to social anxiety and loneliness in adolescent females. Journal of Adolescence, 27, 351-362.

Winston, Joe 1998 Drama, Narrative and Moral Education London, Falmer Warner, Chrsitine 1997 The Edging in of Engagement: exploring the nature of engagement in drama Research in Drama Education, Vol. 2, No. 1, 199721

Young, D. 2000 Reality Drama: the drama classroom as a place for disclosure NADIE Journal Drama Australia 24. 1. 111- 122 